\title{
Comparison of intravenous and topical tranexamic acid in total knee arthroplasty
}

Wenbo Wei ${ }^{1,2}$, Shajie Dang ${ }^{2,3}$, Dapeng Duan ${ }^{1}$ and Ling Wei ${ }^{4^{*}}$

\begin{abstract}
Background: To investigate the clinical effectiveness of intravenous (IV) and topical tranexamic acid (TXA) in patients undergoing total knee arthroplasty (TKA) by comparing safety, efficacy and patient-reported outcomes.

Methods: In this prospective single-blind clinical trial, 64 patients were randomized into two groups ( $n=32$ each). The Intravenous Group was administered TXA 10 mg/kg IV (Reyong, Shandong, China) 10 min prior to tourniquet deflation. In the Topical Group, $1.0 \mathrm{~g}$ TXA diluted in $50 \mathrm{ml}$ of normal saline was injected into the surgical site, which was bathed in the solution for at least 5 min prior to tourniquet deflation. Outcomes included changes in hemoglobin levels, intra-operative, post-operative, and total blood loss, number of transfusions and number of transfused units, patient-reported postoperative Visual Analog Scale (VAS) score for knee pain, and complications.

Results: There were no significant differences in intra-operative blood loss, post-operative blood loss, total blood loss, or post-operative decrease in hemoglobin in the Intravenous Group versus the Topical Group. The number of transfused red blood cell units was significantly greater and-post-operative VAS score was significantly lower in the Intravenous Group. There were no differences in post-operative thromboembolic complications between groups.

Conclusions: Topical TXA is not inferior to IV administration in reducing perioperative blood loss in primary TKA. However, the influence of injection volume of locally applied TXA on post-operative knee pain warrants further investigation.

Trial registration: Clinical ethics committee of Shaanxi People's Hospital (2009), No.125. (ChiCTR 1,800,015,793) registered on 20/04/2018.
\end{abstract}

Keywords: Total knee arthroplasty, Tranexamic acid, Hemoglobin drop, Intravenous injection, Topical injection

\section{Background}

Since the 1960s, total knee arthroplasty (TKA) has become one of the most commonly performed orthopedic operations for the treatment of end-stage knee arthritis. Although TKA provides substantial pain relief and greatly improves orthopedic patients' quality of life, the surgery is associated with complications; in particular, patients undergoing TKA are at risk for bleeding and may require transfusion. As transfusions extend patients' rehabilitation time, prolong length of hospital stay, and represent a considerable cost [1-5], control of bleeding using antifibrinolytic agents such as tranexamic acid (TXA) is a primary focus in TKA [6-10].

\footnotetext{
* Correspondence: wwb560@163.com

${ }^{4}$ Department of Pain, YangLing Demonstration Zone Hospital, No.15 Kangle street, Yang ling, Xi'an 712100, China

Full list of author information is available at the end of the article
}

TXA exerts its antifibrinolytic effects by inhibiting plasminogen, which prevents plasminogen activation and the binding of plasmin to fibrin. This leads to clot stabilization and decreases blood loss in surgical patients [11].

Previous publications have reported on the safety and efficacy of intravenous (IV) TXA for TKA. IV TXA is associated with decreased intra-operative blood loss, transfusion rates, and drop in post-operative hemoglobin concentrations, with no increase in the incidence of post-operative infections or thromboembolic events compared to placebo in patients undergoing orthopedic surgery [12-16]. However, patients with medical conditions such as renal insufficiency, history of previous deep vein thrombosis (DVT), and cerebrovascular and cardiac disease [17] may not tolerate intraoperative IV TXA; topical administration of TXA maybe more appropriate for these patients. Evidence suggests that topical and IV 
TXA have similar safety and efficacy in TKA; however, there is no consensus regarding the most clinically effective regimen for TXA administration. Clinical effectiveness is determined by the therapeutic benefit and adverse effects of a therapeutic approach, as evaluated by patients and clinicians. To the authors' knowledge, no studies comparing different regimens of TXA administration in TKA include patient-reported outcomes, such as patient-reported knee pain, which may have a substantial impact on length of hospital stay and delay rehabilitation, resulting in increased cost associated with surgery. Therefore, the purpose of this study was to investigate the clinical effectiveness of IV and topical TXA in patients undergoing TKA by comparing safety, efficacy, and patient reported outcomes represented by the postoperative Visual Analog Scale (VAS) score for knee pain.

\section{Methods}

This prospective single-blind randomized controlled trial included patients with knee osteoarthritis undergoing unilateral primary TKA performed by senior surgeons at the Department of Orthopedic Surgery, Shannxi Provincial People's Hospital between March, 2010 and October, 2013. The study protocol was approved by the institutional review board (Clinical ethics committee of Shaanxi People's Hospital, Shaanxi, China), and all study participants provided written informed consent.

Inclusion criteria were 1) $\geq 18$ years old; 2) American Society of Anesthesiologists (ASA) score $\leq 3$; and 3 ) planned TKA due to degenerative arthritis of the knee. Exclusion criteria were 1) cardiovascular problems (e.g., myocardial infarction, atrial fibrillation, angina); 2) cerebrovascular conditions (e.g., previous stroke or previous vascular surgery); 3) thromboembolic disorders; and 4) renal insufficiency.

On the day of surgery, included patients were randomized 1:1 into two groups using a random number table and closed envelopes ( $n=32$ each group). The Intravenous Group was administered TXA $10 \mathrm{mg} / \mathrm{kg}$ IV (Reyong, Shandong, China) $10 \mathrm{~min}$ after placement of a loose tourniquet. In the topical group, $1 \mathrm{~g}$ of TXA was diluted in $50 \mathrm{ml}$ of normal saline, injected into the surgical site (posterior and anterior capsule, medial and lateral retinaculum), and the surgical site was soaked in the solution for $5 \mathrm{~min}$ before deflation of the tourniquet. Treatment dose was determined from previous reports that indicate TXA $10-20 \mathrm{mg} / \mathrm{kg}$ IV and 1.0-3.0 g applied topically is effective for reducing blood loss in primary TKA [18-22]. Patients and investigators responsible for evaluating the results were blind to the treatment allocation, while two authors of the study were unblinded on the day of surgery.

All operations were carried out by the same surgeon. Patients' limbs were elevated, bleeding was controlled with an Esmarch bandage, and the tourniquet was inflated to $350 \mathrm{mmHg}$. Operative techniques included a median skin incision followed by a joint incision. Gentamicin cement was used for prosthetic fixation. A polyethylene liner was inserted and wounds were closed. An intra-articular drain was used until post-operative day 2 . All patients were given low-molecular-weight heparin to prevent DVT unless they took another cardiovascular medication before surgery.

Indications for blood transfusion were hemoglobin $<8.0 \mathrm{~g} / \mathrm{dl}$ or hemoglobin $<10.0 \mathrm{~g} / \mathrm{dl}$ with concomitant symptoms of anemia (tachycardia, tachypnea, decreased exercise tolerance) or anemia-related organ dysfunction.

All subjects underwent the same postoperative recovery and rehabilitation program. Routine follow-up was performed at postoperative 2,6 , and 12 weeks, and imaging analysis was performed at postoperative 6 weeks.

\section{Outcomes}

The primary outcome measure was the difference in pre-operative and postoperative hemoglobin levels. Secondary outcome measures include intra-operative, post-operative, and total blood loss, number of transfusions and number of transfused units, post-operative VAS score for knee pain, and complications.

Hemoglobin was measured before the operation and at $24 \mathrm{~h}, 48 \mathrm{~h}$, and $96 \mathrm{~h}$ post-operatively. The difference in pre-operative and postoperative hemoglobin levels was calculated. The postoperative hemoglobin level was defined as the lowest level of hemoglobin among three levels measured postoperatively. The amount of postoperative bleeding was estimated from the drainage volume. The VAS score for knee pain was measured using a $10 \mathrm{~cm}$ visual analog scale.

\section{Statistical analyses}

Statistical analyses were conducted using IBM SPSS 12.0 for Windows (Microsoft Corporation, Redmond WA). Data are expressed as mean \pm standard deviations (SDs). Continuous variables are presented as means and standard deviations. Categorical variables are summarized as the number and percentage of the total study population. Normally distributed continuous variables were compared with a two-sided independent $\mathrm{t}$-test. Categorical variables were combined with Chi-square. Statistical significance was defined as $P<0.05$.

\section{Results}

This prospective randomized clinical trial included 64 patients undergoing TKA due to degenerative arthritis of the knee. Patients' baseline demographic and clinical characteristics are shown in Table 1. Mean age of patients in the Intravenous Group was 66.47 years (range, 56-79 years); mean age of patients in the Topical Group was 66.43 years (range, $54-78$ years). There were no significant differences in age, gender, height, weight, body 
Table 1 Patient baseline demographic and clinical characteristics

\begin{tabular}{llll}
\hline & IV group & Topical group & $P$ value \\
\hline Age (year) & $66.47 \pm 8.28$ & $66.43 \pm 7.69$ & 0.984 \\
Male: Female & $14: 18$ & $16: 16$ & 0.25 \\
Body mass index $(\mathrm{kg} / \mathrm{m} 2)$ & $32.39 \pm 3.73$ & $34.15 \pm 5.02$ & 0.084 \\
American Society of Anesthesiologists classification & $2.03 \pm 0.14$ & $1.79 \pm 0.26$ & 0.153 \\
hemoglobin $(\mathrm{g} / \mathrm{l})$ & $11.26 \pm 1.60$ & $10.97 \pm 1.19$ & 0.21 \\
Red blood cell $\left(10^{12} / \mathrm{l}\right)$ & $3.72 \pm 0.75$ & $4.05 \pm 1.04$ & 0.35 \\
prothrombin time(s) & $11.51 \pm 3.51$ & $11.85 \pm 4.62$ & 0.16 \\
\hline
\end{tabular}

mass index, prothrombin time, hemoglobin, American Society of Anesthesiologists score, or comorbidities between the two groups.

There were no significant differences in intra-operative blood loss (intravenous: $122.81 \pm 41.60 \mathrm{~mL}$ [range 60$200 \mathrm{~mL}$ ] vs. topical: $109.06 \pm 33.38 \mathrm{~mL}$ [range 70-200 mL]), post-operative blood loss (intravenous: $125.31 \pm 35.649 \mathrm{~mL}$ [range $80-240 \mathrm{~mL}$ ] vs. topical: $110.00 \pm 30.900 \mathrm{~mL}$ [range 20-180 mL]), or total blood loss (intravenous: $254.38 \pm$ $52.544 \mathrm{~mL}$ [range 140-420 mL] vs. topical: $210.00 \pm$ $41.426 \mathrm{~mL}$ [range 100-400 mL]) in the Intravenous Group versus the Topical Group.

There were no significant differences in post-operative drop in hemoglobin (intravenous: 2.84 \pm 0.68 [range 1.95-4.36] vs. topical: $2.66 \pm 0.60$ [range 1.73-3.84]). However, the number of transfused red blood cell units was significantly greater in the Intravenous Group (42 units red cell suspension; 1.28 units/patient) compared to the Topical Group (20 units red cell suspension; 0.63 units/patient) $(P<0.05)$ (Table 2).

Post-operative VAS score was significantly lower in the Intravenous Group compared to the Topical Group at 12 and $24 \mathrm{~h}$ after surgery. In the Intravenous Group, the VAS score was $5.41 \pm 0.875$ at post-operative $12 \mathrm{~h}$ and $3.88 \pm 0.976$ at post-operative $24 \mathrm{~h}$. In the Topical Group, the VAS score was $6.69 \pm 0.998$ at post-operative $12 \mathrm{~h}$ and $5.50 \pm 0.842$ at post-operative $24 \mathrm{~h}$. At $48 \mathrm{~h}$ after surgery, there was no significant difference in VAS score (intravenous: $2.75 \pm 0.568$ vs. topical: $2.97 \pm 0.647$ ).

There were no differences in post-operative thromboembolic complications between the Intravenous Group and Topical Group. No infusion-related complications related to TXA dosing, no allergic reactions, and no deaths were reported.

\section{Discussion}

This study sought to compare the clinical effectiveness of IV and topical TXA in primary TKA using a prospective randomized controlled trial. Our results indicate that topical TXA and IV-TXA have similar safety and efficacy for reducing perioperative blood loss in TKA. There was no significant difference in the change in hemoglobin levels or therapeutic effect between topical TXA and IV administration. However, patients reported a significantly higher VAS score for knee pain in the Topical Group compared to the Intravenous Group at 12 and $24 \mathrm{~h}$ after surgery; there was no significant difference at $48 \mathrm{~h}$. The higher VAS score at $12-24 \mathrm{~h}$ after the surgery may result from increased pressure in the knee joint due to the topical administration of TXA. A previous study [22] found that topical administration of TXA via a drain tube significantly increased joint swelling following TKA; rehabilitation in these patients took longer because of the pain. Further studies are warranted to elucidate the

Table 2 Outcomes

\begin{tabular}{lll}
\hline & IV group & Topical group \\
\hline Post-Operative Transfusion (Units) & 1.28 & 0.63 \\
Intra-operative blood loss (ml) & $122.81 \pm 41.60 \mathrm{~mL}$ & $109.06 \pm 33.38 \mathrm{ml}$ \\
Post-operative blood loss $(\mathrm{ml})$ & $125.31 \pm 35.649 \mathrm{~mL}$ & $110.00 \pm 30.900 \mathrm{~mL}$ \\
Total blood loss & $254.38 \pm 52.544 \mathrm{~mL}$ & $210.00 \pm 41.426 \mathrm{~mL}$ \\
Hb Fall (mg/dl) & $2.84 \pm 0.68$ & $2.66 \pm 0.60$ \\
VAS & & 0.071 \\
$12 \mathrm{~h}$ & $5.41 \pm 0.875$ & 0.143 \\
$24 \mathrm{~h}$ & $3.88 \pm 0.976$ & $6.69 \pm 0.998$ \\
$48 \mathrm{~h}$ & $2.75 \pm 0.568$ & $5.50 \pm 0.842$ \\
comorbidities & no & 0.001 \\
\hline
\end{tabular}


clinical and economic implications of the increased VAS score in patients receiving topical administration of TXA in primary TKA.

The current study confirmed the results of previous studies showing that IV and topical TXA have similar safety and efficacy profiles in TKA [12-16]. However, to the authors' knowledge, this is the first study to include patient-reported outcomes in a study investigating the effectiveness of different regimens of TXA administration. Results showed that IV TXA administration may be the optimal approach as patients reported less pain during the initial $24 \mathrm{~h}$ after surgery, suggesting this regimen is associated with the potential for faster rehabilitation and shorter length of hospital stay.

TKA has good outcomes for the treatment of end-stage knee arthritis; however, blood loss may vary from $800 \mathrm{ml}$ to $1800 \mathrm{ml}$ [1-5], and the incidence of transfusion may range from 11 to $67 \%$ [6, 7]. Allogeneic blood transfusions are an economic burden and may result in the transmission of bloodborne pathogens, an immunomodulatory response, and periprosthetic joint infection [23]. Control of perioperative blood loss is associated with lower transfusion rates and shorter length of hospital stay $[24,25]$. Currently, perioperative blood loss is controlled by the use of a tourniquet, hypotension, re-infusion drains, bipolar radiofrequency ablation, and antifibrinolytic drugs such as TXA.

TXA is an anti fibrinolytic drug that is used to reduce hemorrhage. TXA enhances microvascular hemostasis by preventing the dissolution of fibrin clots [26]. TXA is rapidly distributed to the synovial fluid and synovial membranes. The biological half-life of TXA in synovial fluid is estimated at $3 \mathrm{~h}$ [27]. TXA is eliminated through glomerular filtration; excretion of an Intravenous infusion of $10 \mathrm{mg} / \mathrm{kg}$ may reach $30 \%$ at $1 \mathrm{~h}, 55 \%$ at $3 \mathrm{~h}$, and $90 \%$ at $24 \mathrm{~h}$ [27]. Methods of TXA administration include intravenous or Intramuscular injection or oral, [28], which result in maximal plasma levels of TXA at 5 to $15 \mathrm{~min}, 30 \mathrm{~min}$, or 2 hours, respectively $[29,30]$. TXA may also be administered by intra-articular injection.

Renal insufficiency, previous history of DVT, and cerebrovascular and heart disease are contraindications to the use of IV TXA. In these patients, topical application of TXA to the knee joint is considered the safest route of administration as drug activity is delivered directly to the site of action and systemic sequelae are limited [31]. To target the bleeding, TXA is applied locally before wound closure. This reduces the significant increase in local fibrinolysis associated with tourniquet release [32]. Akizuki first described the use of topical TXA in orthopedic surgery [33]. They found that intra-articular application of $250 \mathrm{mg}$ TXA in $50 \mathrm{ml}$ saline effectively reduced bleeding in patients with cementless TKA. Since then, other studies have demonstrated similar outcomes.
A prospective, double-blind, placebo-controlled randomized trial of 124 patients who received $1.5 \mathrm{~g}$ or $3 \mathrm{~g}$ of TXA or placebo in $100 \mathrm{ml}$ of saline in the joint after surgery showed that TXA administration resulted in a significantly lower drop in hemoglobin loss and blood loss with no differences in thromboembolic complications. In accordance with our findings, a prospective randomized study involving 89 patients showed no significant difference in lowest post-operative hemoglobin level or total drain output following topical administration of $2.0 \mathrm{~g}$ TXA or $10 \mathrm{mg} / \mathrm{kg}$ TXA IV [34].

The authors acknowledge that the current study has several limitations. First, the study was conducted in a small sample of patients. Second, the clinical characteristics of thromboembolic complications were not documented. A longer follow-up period is required to adequately compare the safety profile and functional outcome differences between the two groups.

\section{Conclusion}

This study showed that topical TXA is not inferior to IV administration in reducing perioperative blood loss in primary TKA. However, the VAS score in the Topical Group was significantly higher than the Intravenous Group at 12 and $24 \mathrm{~h}$ after surgery. The influence of the injection volume of locally applied TXA on post-operative pain in surgical patients warrants further investigation.

\section{Abbreviations \\ DVT: Deep vein thrombosis; IV: Intravenous; TKA: Total knee arthroplasty; TXA: Tranexamic acid; VAS: Visual Analog Scale}

\section{Acknowledgements \\ We greatly appreciate the assistance of the company Medjaden Bioscience Limited., which provided English language editing.}

\section{Availability of data and materials}

All data generated or analyzed during this study are included in this article. We confirm that the Availability of data and materials refers to the raw data generated and used for this study. Meanwhile, the datasets used and/or analyzed during the current study are available from the corresponding author on reasonable request.

\section{Authors' contributions \\ WBW was in charge and contributed to all stages of the present study.; DPD was responsible for participated in the design of the study, made revisions of the manuscript and approved the final version. WBW and SJD contributed to interpreting the data and writing the final manuscript; LW was a contributor in writing and editing the manuscript. All authors read and approved the final manuscript.}

Ethics approval and consent to participate

The study protocol was approved by the Institutional Review Board of Shaanxi provincial people Hospital ((the ethics approval number provided by the board was $2,009,125)$ ), and written informed consent was obtained from all study participants.

Competing interests

The authors declare that they have no competing interests. 


\section{Publisher's Note}

Springer Nature remains neutral with regard to jurisdictional claims in published maps and institutional affiliations.

\section{Author details}

'Department of Orthopedics, Shaanxi Province People Hospital, Xi'an 710004, China. ${ }^{2}$ Xi'an JiaoTong University, Xi'an 710004, China. ${ }^{3}$ Department of Anesthesiology, Shaanxi Provincial Cancer Hospital, Xi'an 710001, China. ${ }^{4}$ Department of Pain, YangLing Demonstration Zone Hospital, No.15 Kangle street, Yang ling, Xi'an 712100, China.

\section{Received: 6 November 2017 Accepted: 31 May 2018}

Published online: 13 June 2018

\section{References}

1. Benoni $G$, Fredin $H$. Fibrinolytic inhibition with tranexamic acid reduces blood loss and blood transfusion after knee arthroplasty: a prospective, randomized, double-blind study of 86 patients. J Bone Joint Surg (Br). 1996;78:434

2. Cushner FD, Friedman RJ. Blood loss in total knee arthroplasty. Clin Orthop Relat Res. 1991;269:98

3. Hiippala S, Strid L, Wennerstrand M, et al. Tranexamic acid (Cyklokapron) reduces perioperative blood loss associated with total knee arthroplasty. $\mathrm{Br}$ J Anaesth. 1995:74:534.

4. Lotke PA, Faralli VJ, Orenstein EM, et al. Blood loss after total knee replacement: effects of tourniquet release and continuous passivemotion. J Bone Joint Surg Am. 1991;73:1037.

5. Sehat KR, Evans R, Newman JH. How much blood is really lost in total knee arthroplasty? Correct blood loss management should take hidden loss into account. Knee. 2000;7:151.

6. Bierbaum BE, Callaghan JJ, Galante JO, et al. An analysis of blood management in patients having a total hip or knee arthroplasty. J Bone Joint Surg Am. 1999:81(1):2

7. Noticewala MS, Nyce JD, Wang W, et al. Predicting need for allogeneic transfusion after total knee arthroplasty. J Arthroplast. 2012;27(6):961.

8. Sharrock NE, Go G, Williams-Russo P, et al. Comparison of extradural and general anaesthesia on the fibrinolytic response to total knee arthroplasty. Br J Anaesth. 1997;79(1):29

9. Sculco TP. Global blood management in orthopaedic surgery. Clin Orthop Relat Res. 1998;357:43.

10. Bezwada HR, Nazarian DG, Henry DH, et al. Blood management in total joint arthroplasty. Am J Orthop. 2006;35(10):458.

11. Jansen J, Andreica S, Claeys M, et al. Use of tranexamic acid for an effective blood conservation strategy after total knee arthroplasty. Br J Anaesth. 1999;83:596.

12. Yang ZG, Chen WP, Wu LD. Effectiveness and safety of tranexamic acid in reducing blood loss in total knee arthroplasty: a meta-analysis. J Bone Joint Surg Am. 2012;94(13):1153.

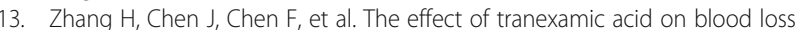
and use of blood products in total knee arthroplasty: a meta-analysis. Knee Surg Sports Traumatol Arthrosc. 2012;20(9):1742.

14. Dahuja A, Dahuja G, Jaswal $V$, et al. A prospective study on role of tranexamic acid in reducing postoperative blood loss in total knee arthroplasty and its effect on coagulation profile. J Arthroplast. 2013;29:733.

15. Karam JA, Bloomfield MR, Diiorio TM, et al. Evaluation of the efficacy and safety of tranexamic acid for reducing blood loss in bilateral total knee arthroplasty. J Arthroplast. 2014;29(3):501.

16. Tan J, Chen H, Liu Q, et al. A meta-analysis of the effectiveness and safety of using tranexamic acid in primary unilateral total knee arthroplasty. J Surg Res. 2013;184(2):880.

17. McCormack PL. Tranexamic acid: a review of its use in the treatment of hyperfibrinolysis. Drugs. 2012;72:585-617.

18. Kagoma YK, Crowther MA, Douketis J, et al. Use of antifibrinolytic therapy to reduce transfusion in patients undergoing orthopedic surgery: a systematic review of randomized trials. Thromb Res. 2009;123(5):687

19. Patel JN, Spanyer JM, Smith LS, Huang J, Yakkanti MR, Malkani AL. Comparison of intravenous versus topical tranexamic acid in total knee arthroplasty: a prospective randomized study. J Arthroplasty. 2014;29(8):1528-31.

20. Alshryda S, Sarda P, Sukeik M, et al. Tranexamic acid in total knee replacement: a systematic review and meta-analysis. J Bone Joint Surg Br. 2011;93(12):1577.
21. Soni A, Saini R, Gulati A, Paul R, Bhatty S, Rajoli SR. Comparison between intravenous and intra-articular regimens of tranexamic acid in reducing blood loss during total knee arthroplasty. J Arthroplasty. 2014;29(8):1525.

22. Sarzaeem MM, Razi M, Kazemian G, Moghaddam ME, et al. Comparing efficacy of three methods of tranexamic acid administration in reducing hemoglobin drop following total knee arthroplasty. J Arthroplast. 2014;29(8):1521-4.

23. Alter HJ, Klein HG. The hazards of blood transfusion in historical perspective. Blood. 2008;112(7):2617-26.

24. Raut S, Mertes SC, Muniz-Terrera G, et al. Factors associated with prolonged length of stay following a total knee replacement in patients aged over 75 . Int Orthod. 2012;36(8):1601.

25. Diamond PT, Conaway MR, Mody SH, et al. Influence of hemoglobin levels on inpatient rehabilitation outcomes after total knee arthroplasty. J Arthroplast. 2006;21(5):636.

26. Katsumata S, Nagashima M, Kato K, et al. Changes in coagulation-fibrinolysis marker and neutrophil elastase following the use of tourniquet during total knee arthroplasty and the influence of neutrophil elastase on thromboembolism. Acta Anaesthesiol Scand. 2005;49(4):510.

27. Ahlberg A, Eriksson O, Kjellman H. Diffusion of tranexamic acid to the joint. Acta Orthop Scand. 1976:47(5):486.

28. TanakaN SH, Sato E, et al. Timing of the administration of tranexamic acidfor maximum reduction in blood loss in arthroplasty of the knee. J Bone Joint Surg (Br). 2001;83:p:702.

29. Sano M, Hakusui $H$, Kojima $C$, et al. Absorption and excretion of tranexamic acid following intravenous, intramuscular and oral administrations in healthy volunteers. Jpn J Clin Pharmacol Ther. 1976;7:375.

30. Benoni G, Bjorkman S, Fredin H. Application of pharmacokinetic data from healthy volunteers for the prediction of plasma concentrations of tranexamic acid in surgical patients. Clin Drug Investig. 1995;10:280.

31. Seo JG, Moon YW, Park SH, et al. The comparative efficacies of intraarticular and IV tranexamic acid for reducing blood loss during total knee arthroplasty. Knee Surg Sports Traumatol Arthrosc. 2013;21:1869.

32. Aglietti $P$, Baldini $A$, Vena $L M$, et al. Effect of tourniquet use on activation of coagulation in total knee replacement. Clin Orthop Relat Res. 2000;371:169.

33. Akizuki S, Yasukawa Y, Takizawan T. A new method of hemostasis for cementless total knee arthroplasty. Bull Hosp Jt Dis. 1997;56:222.

34. Patel JN, Spanyer JM, Smith LS, Huang J, et al. Comparison of intravenous versus topical tranexamic acid in total knee arthroplasty: a prospective randomized study. The Journal of Arthroplasty. 2014:29:1528-31.

\section{Ready to submit your research? Choose BMC and benefit from:}

- fast, convenient online submission

- thorough peer review by experienced researchers in your field

- rapid publication on acceptance

- support for research data, including large and complex data types

- gold Open Access which fosters wider collaboration and increased citations

- maximum visibility for your research: over $100 \mathrm{M}$ website views per year

At BMC, research is always in progress.

Learn more biomedcentral.com/submissions 